\title{
SocArXiv
}

Preprint : April 5, 2019

osf.io/0000

\section{Do Grants Improve the Outcomes of University Students in a Context with High Dropout Rates? Evidence from a Matching Approach.}

\author{
Marta Facchini \\ Observatoire Sociologique du Changement \\ Sciences Po
}

\author{
Moris Triventi \\ Department of Sociology and Social Research \\ Loris Vergolini \\ FBK-IRVAPP \\ University of Trento
}

\begin{abstract}
We investigate whether grants improve the academic outcomes of students from socioeconomically disadvantaged families and, by this way, contribute to reducing inequalities of educational opportunities. Differently from most previous studies, we focus on Italy, a context with high dropout rates and prolonged duration of higher education studies. To estimate the causal effect of the grant we followed a counterfactual approach relying on a three-step reweighting matching procedure, applied to survey data collected at national level by ISTAT on a sample of upper secondary school graduates in 2004 and 2007 . We find that grants reduce drop-out and increase timely graduation, with larger effects among males and students in Central-Southern Italy, those who are more at risk of withdrawal from university.
\end{abstract}

Keywords: Financial aid, drop-out, timely graduation, CEM, entropy balancing.

In the last century, enrolment in higher education has been growing dramatically in many countries, suggesting an increased demand from families and students of receiving advanced instruction and training (Marginson 2016). However, despite the growing enrolments, not all the students who enter higher education are able to successfully conclude their studies obtaining a degree, and many students take longer time to complete their degree program than expected from the formal duration (OECD 2010). Furthermore, there is evidence that social background not only affects the chances to enrol in higher education, but also persistence and 
timely completion of degree, thereby amplifying inequalities in university degree attainment (Triventi and Trivellato 2009).

In many countries, universities and institutions of higher education face the challenge of improving student success, by reducing dropout rates and time-to-degree. The HEDOCE study, a recent comparative study on higher education dropout and completion in Europe, found that study success is regarded as important in three quarters of the 35 European countries surveyed and in almost half of the countries it is high or very high on the policy agenda (Vossensteyn et al. 2015). There is great variety in the policy instruments governments use trying to increase study success. They include funding and financial incentives (e.g. grants, loans, free services, accommodation, tax reductions), the provision of information and support for students (e.g. counselling, career guidance related to study and future job opportunities, tutoring, etc.), and interventions on the characteristics of higher education (e.g. selection at entry, duration of study, types of degrees offered, quality assurance and accreditation, etc.).

In this article, we focus on students' grants, a specific form of financial aid, and we are interested in understanding whether it is an effective tool for improving students' success. On one hand, student aid might have a crucial role in reducing dropout rates and improving timely completion of degree, thereby limiting the loss of talent and boosting the effectiveness of the higher education system. On the other hand, by being mostly targeted to a population of low income students, this policy instrument has the potential of reducing inequality of educational opportunity at higher levels of education.

There is a consolidated empirical literature on the effect of grants in the United States. While scholars have mainly addressed the effect of financial aids on university enrolment, in the last decade they have expanded the focus on persistence and timely degree completion, also thanks to greater availability of longitudinal data (Castleman and Long 2016; Page and Scott-Clayton 2016). A n umber of studies report that the increase in the amount awarded by need-based grants diminished dropout and raised performance and completion (Bettinger 2015; Castleman and Long 2016). The empirical literature also suggests that financial aid has a positive impact on student success, especially if combined with assistance, tutoring and study groups (Deming and Dynarski 2009; Angrist et al. 2009; Page et al. 2017) and it is particular effective for students who were less academically successful (Goldrick-Rab et al. 2016).

Few studies analyzed the impact of student aid in Europe, arriving at contrasting results. Some studies found that extension of financial aid has significant effects in reducing dropouts and increasing timely completion of degree in Denmark (Arendt 2013), but other reforms of financial aids system in Finland did not bring major changes (Häkkinen and Uusitalo 2003) or they even reduced pass rates of low-achieving first-year students in the Netherlands (Leuven et al. 2010).

In our work we focus on the Italian higher education system, in which various studies analysed the role of student grants, but always focusing on specific universities and regions (Mealli and Rampichini 2012; Agasisti and Murtinu 2016; Sneyers et al. 2016)( Graziosi 2014), with limited possibility of generalization of results. Italy is an interesting case study for at least two reasons. First, it has comparatively a very high rate of dropouts from higher education and long time to degree as well (Triventi and Trivellato 2009; Aina et al. 2011). Second, the system of financial support to students is not well-developed and the share of students who have access to public 
financial support is limited compared to other Western countries (Eurydice 2018). We are therefore interested in understanding whether grants may be an effective tool for improving student success and reducing social inequalities in such challenging context.

Our contribution is threefold. First, we provide the first assessment of the effect of the main public grant awarded in Italy by the 'Regional Authority for the Right to Education' (Ente Regionale per il diritto allo studio) on a representative sample of a recent cohort of university students who entered the system in the mid-2000s, after the 'Bologna process'. Second, we show how it is possible to provide credible estimates of the causal effect of grants with observational survey data, taking into consideration the challenge posed by potential unobserved factors. Third, we do not only provide estimates of average effects of student grants, but we also investigate possible heterogeneity across groups of students defined by gender and geographical area. The article is structured as follows. In the next section, we present the theoretical framework and expectations, while in the third section we briefly describe the main features of higher education and financial aid system in Italy. Data, variables and methods are described in the fourth section, whereas the fifth section presents the research findings and sensitivity checks. Finally, the last section discusses the results and concludes ${ }^{1}$.

\section{Theoretical Framework}

In this section we review theoretical arguments that aim to explain why student grants may (or may not) be an effective instrument to reduce dropouts in higher education and improve timely completion of degrees.

A prominent model explaining the heterogeneous chances of making specific educational transitions is the rational choice theory. While most of the studies focus on educational transitions between educational levels, it is also possible to apply this theoretical reasoning to the decision of remaining enrolled in higher education or withdraw without obtaining a degree. In the sociological version of rational choice theory, individuals - when making educational-related decisions - consider the costs, the benefits and the probability of success associated with the different educational options (Gambetta 1987). Students who perceive the university studies as too difficult, costly and bringing less benefits in the short and longer term will have higher chances of dropout. Financial aids and students' grants may act specifically to reduce the expected and actual costs of studying at university, by compensating the expenses for tuition fees, study material, living costs, etc. (Daniel et al. 1999). All else being equal, a reduction of the expected costs should lead to an increase in the utility of staying enrolled and attaining a degree.

Furthermore, since grants are assigned to students from lower income families, receiving regularly public financial support should diminish their need to work while studying at university, which has been found to be detrimental for study progression (Triventi 2014a). Without the need of working during the period of lectures, students with the grant have the possibility to attend regularly the classes, which may be helpful in the preparation of examinations and may improve students' academic performance (Credé et al. 2010; Denning 2017). Regularly participating in the classes is also a way by which students under public support may experience an improvement in their academic and social integration in the university environment, two key drivers of persistence and student success in higher education in the classical model of Tinto (1975). Finally, grants could affect both intrinsic and extrinsic individual motivation. On one

\footnotetext{
${ }^{1}$ This article was compiled using the SocArXiv template (Marcum 2016)
} 
side, it has been suggested that students receiving public support could feel to be positively valued by the institution and perceive a stronger sense of responsibility (Goldrick-Rab et al. 2009). On the other side, students have external incentives to put additional effort to progress adequately in the studies to receive additional funding in the following years, since the possibility to keep the grant in Italy is conditional to maintaining a given standard of credits accumulation and academic performance (see the next section). All these arguments, thus, suggest that financial aid may have a positive effect on student success in higher education. We therefore hypothesize that grants contribute to reduce the risk of dropout and increase the probability of completing the degree on time (Hypothesis 1a).

Nonetheless, there are also reasons that cast doubts on the effectiveness of student grants in reducing dropouts and time-to-degree in the Italian case. First, in Italy there is no systematic system of orientation guiding students from upper secondary education to university. There is evidence that students have pretty distorted visions about the expected returns, costs and probability of success in the various fields of study, and such misperceptions are also socially stratified (Abbiati and Barone 2017). This means that students and families are let alone in the decision about which university and field of study to attend and this could bring to a considerable frustration by first year students who chose a degree program that does not fit their expectations and needs (Alon and Tienda 2005). In this situation, receiving a grant can do very little in fostering persistence and increasing credits accumulation.

A second reason refers to students' previous academic preparation. Heckman (2006) holds that the effect of investment in education follows a dynamic of capital accumulation, therefore students without adequate initial knowledge will find remarkably more difficult to gain additional skills, within a process of 'learning begets learning'. Even if grants in Italy are provided to first-year students who obtained a good grade in the final examination in upper secondary education, there is a great variability in grading standards across geographical areas and school tracks, and students with the same grade may have very different levels of academic preparation (Argentin and Triventi 2015). Therefore, the lack of adequate previous basic skills for grant holders could be a counterforce limiting the effectiveness of financial aids in improving student success. This can be exacerbated by the fact that disadvantaged students with inadequate academic preparation could develop psychological stress related to frustration and fatigue, since understanding the lessons and the material would be harder for them (Goldrick-Rab et al. 2009).

Finally, one could argue that grants in principle may affect students' persistence patterns, but that in the Italian case the level of support is inadequate to activate the virtuous circle described above. If the amount of money is not sufficient to cover the direct costs, for instance, the students from low income families enrolled outside their hometown will have to find a job during their studies and this can make study progression and attachment to the university more difficult, thereby raising the risks of withdrawal or extending time-to-degree. Thus, these rationales suggest that grants might have little or no eï̆Ǎect on students' likelihood of dropout out and time-to-degree. (Hypothesis 1b).

\section{The Italian Higher Education System}

For a long time, Italian higher education has been organized as a unitary system, constituted exclusively by universities offering mostly long-degree programs. For this reason we will use the expressions 'higher education' and 'university' interchangeably. In 2001, the Bologna 
Process restructured the degree programs by introducing a two-level structure constituted by 3 -year long bachelor programs followed by 2-year long master programs, in most of the academic disciplines. The amount of learning of a full-time year corresponds to 60 ECTS, with each credit corresponding to a workload of 25 hours of lectures and personal study.

Looking at the transition from upper secondary education to university, three notable features stand out. First, upper secondary graduates can enroll at university regardless of previous performance and high school track. Thus, not only students from the academic track, but also those from technical and vocational schools can enroll at university. Second, entry restrictions at the national level are present only for some fields, notably medicine and health professions, veterinary science, and architecture. Additionally, universities can restrict the maximum number of available places in specific degree programs, but most of them do not have any numerus clausus. Third, Italy lacks a systematic and effective system of orientation supporting upper secondary graduates in the choice of university and field of study.

The public support system for university students is underdeveloped and, coherently with the Italian welfare regime, the student is considered as a 'child in a family social system' (Daniel et al. 1999). The implicit expectation is that the parents will contribute substantially to support the student during university studies (Triventi 2014b). Therefore, the system of public financial aid is not very generous: the proportion of beneficiaries $(9 \%)$ and the coverage of educational and living costs for the grant holders are comparatively low (OECD 2017).

The main forms of support are the mean-tested fee-waiver and the grant awarded by the 'Regional Authority for the Right to Education' (Ente regionale per il diritto allo studio). The average amount of the grant is about 3.300 âĆn̆, which is two times the average fees (Eurydice 2018). However, the maximum of the grant is awarded only to the students who transferred to a distant city in order to attend university. In this case, financial aid cover about one sixth of the living cost $(9,000 €$ ) (Finocchietti et al. 2015). Services and subsides for food and housing are residual and demand for student loans is marginal as well (in 2015 less than $1 \%$ of students subscribed a loan). Importantly, prospective students are not able to plan their studies according to the level of support available, for two reasons: 1) they will know if they are considered eligible (idonei) only after having enrolled; 2) some universities are not able to offer support to all eligible applicants, due to the lack of financial resources. The students who meet the grant eligibility requirements but do not receive the financial aid are called idonei non beneficiari and are mostly concentrated in the South. Grant renewal is conditional on the completion of half of the workload of the academic year (30 credits). Lastly, families can deduce $19 \%$ of tuition and fees regardless of their income.

While the first-time entry rates are comparable with the other European countries (45\%) (OECD 2018) and despite the educational expansion, Italy has still a lower rate of graduates than most of the OECD countries (Viesti 2016). This is the result of several problems that have plagued the Italian higher education system since the second half of the XX century. First, Italy displays very high dropout rates (Triventi and Trivellato 2009), and delays in study progression and graduation, especially in the South (Aina et al. 2011). Second, access to higher education and the choice of field of study as well as persistence and timely degree are subject to high level of social inequalities (Argentin and Triventi 2011; Triventi et al. 2017). 


\section{Data, Variables and Methods}

\subsection{Data, Variables and Analytical sample}

We analyse data from the Survey on Upper Secondary Graduates (USG hereafter) carried out by the Italian Statistical Institute (ISTAT) almost every three years since 1998. The survey adopts a two-stage probability sampling design. The first stage units are upper secondary schools stratified according to region of residence, type of school and size. The second stage units are the upper secondary school students who graduated three years before the survey. A detailed description of the sampling procedure of the two waves can be found in the ISTAT's methodological manuals (ISTAT 2007, 2011).

For our purposes, we consider the 2007 and 2011 waves carried out on upper secondary graduates respectively in 2004 and 2007. We consider only these two editions because in the other waves the information on grants or field of study was not collected. As stated in the introduction, USG data are a valuable source of information for our purposes. It is a reliable source of data on university students and it allows us to evaluate the effectiveness of a national programme on a representative sample of university students, which has not been done before in Italy.

To answer the research questions, we rely on two analytical samples, one for each outcome of interest: university dropout and timely graduation. The first sample is used to examine the effect of financial aid on dropout risks and it includes the students who enrolled immediately after the upper secondary school graduation or one year later. In this way, we can observe if they dropout in the first two years after enrolment, which is the critical period with the highest dropout risk (Checchi 2016). One has to consider that our sample restriction only partially reduces the target population, since in Italy the vast majority of students enter university immediately after the end of upper secondary school (around 85\%). For the second sample, we use the 2011 wave, thus retaining only those students who enrolled immediately after the diploma, since they are the only group observable for the legal duration of the program. Even if the legal duration of the Bachelor is three years, we will consider students as timely graduated if they complete their studies in four years. This choice is due to the fact that in the 2011 wave it is not possible to identify students who have graduated in three years. Moreover, in Italy, graduation within the legal duration of studies is very uncommon.

The treatment is a dummy variable that takes value one (treated) for students who receive the grant awarded by the Ente Regionale per il Diritto allo Studio at least one time during university studies and it takes value zero otherwise (controls).

In the USG data, we have a rich set of variables that are useful to adjust for the differences in the composition between the group of students who received the grant and the other students. These covariates include socio-demographic characteristics (sex, parental education, parental social class, geographic area of residence), secondary education studies (final marks in lower and upper secondary education, high school track, grade retention), university studies (type of degree, field of study), as well as contextual labour market indicators (unemployment rate and youth unemployment rate). These characteristics might be related to the chances of applying and receiving a grant, and can also affect independently the chances of degree completion. Tables A.1 and A.2 in the appendix provide a detailed explanation of the coding of these variables and descriptive statistics. 


\subsection{Identification Strategy}

To estimate the causal effect of the grant we followed a counterfactual approach relying on a three-step reweighting matching procedure. Instead of using the classical propensity score matching estimator, whose limits have been recently stressed by King and Nielsen (2016), we integrated two recently developed matching procedures: the coarsened exact matching (CEM) (Blackwell et al. 2009) and the entropy balancing method (EBM) (Hainmueller 2012).

First, CEM is applied to restrict the data to the region of common support. Using the control variables specified above and appropriately recoded, we implemented an exact matching: the algorithm selects the counterfactual for each treated subject (students who received a grant) using the control cases (students who did not receive a grant) that have identical values on the coarsened variables. In particular, the algorithm creates one stratum for each combination of the new variables; it then classifies every observation in a stratum and discards the stratum (and the observations inside it) if it does not contain at least one treated case and one control case. In the second step, the EBM algorithm weighs the observations in order to balance mean, variance and skewness of the covariates in the treatment and control groups. The weights obtained from this procedure can be used with standard estimators to identify the average treatment effect for the treated (ATT).

Figure 1 shows that our matching approach was successful in balancing the composition of the two groups in terms of socio-demographic characteristics and previous educational career, since almost all the standardized differences in the means of treated and control group are approximately zero.

In the third and last step, to estimate the effect of the grant on dropout and timely graduation, we applied binomial logistic regression on the analytical sample selected in step 1 and weighted the observations using the weights created in step 2 .

To ease the interpretation, we present the results in terms of average partial effects (APE), which can be interpreted as the average effect on the outcome of interest (e.g. probability of dropout) of having received a grant for the grant holders. Given the setting employed in this paper, the APE represents the ATT. With this approach, it is also possible to analyse the heterogeneity of the effects confronting sub-groups of students. We did this by comparing firstly female and male students and, secondly, students enrolled in northern and southern universities.

Although our matching strategy combines the strengths of CEM and EBM and it provides a very good balance between the treated and the control group, this approach is still based on the assumption of selection on observables, i.e. we are assuming that, conditioning on the relevant covariates, treated and controls are equivalent. To test the plausibility of this assumption, we followed Nannicini et al. (2007)and analysed the sensitivity of the estimated treatment effects simulating the presence of a potential confounder. The main idea is that the result of the analysis can be considered robust if introducing a simulated unobserved variable in the models does not alter considerably the estimated effect of having received the grant. This unobservable variable $(U)$ is chosen to mimic the behaviour of some important factors for the phenomenon under scrutiny such as sex, geographic area, social origins and school career. Examples of potentially relevant unobserved variables are student's motivation and educational aspirations. We calibrated the distribution of $U$ according to these covariates and, since the routine requires a binary confounder, we dichotomized the covariates that have more than two categories. The routine includes $U$ in the set of control variables and estimates 
Figure 1: Standardized differences in the means of covariates: before and after the matching by entropy balance.

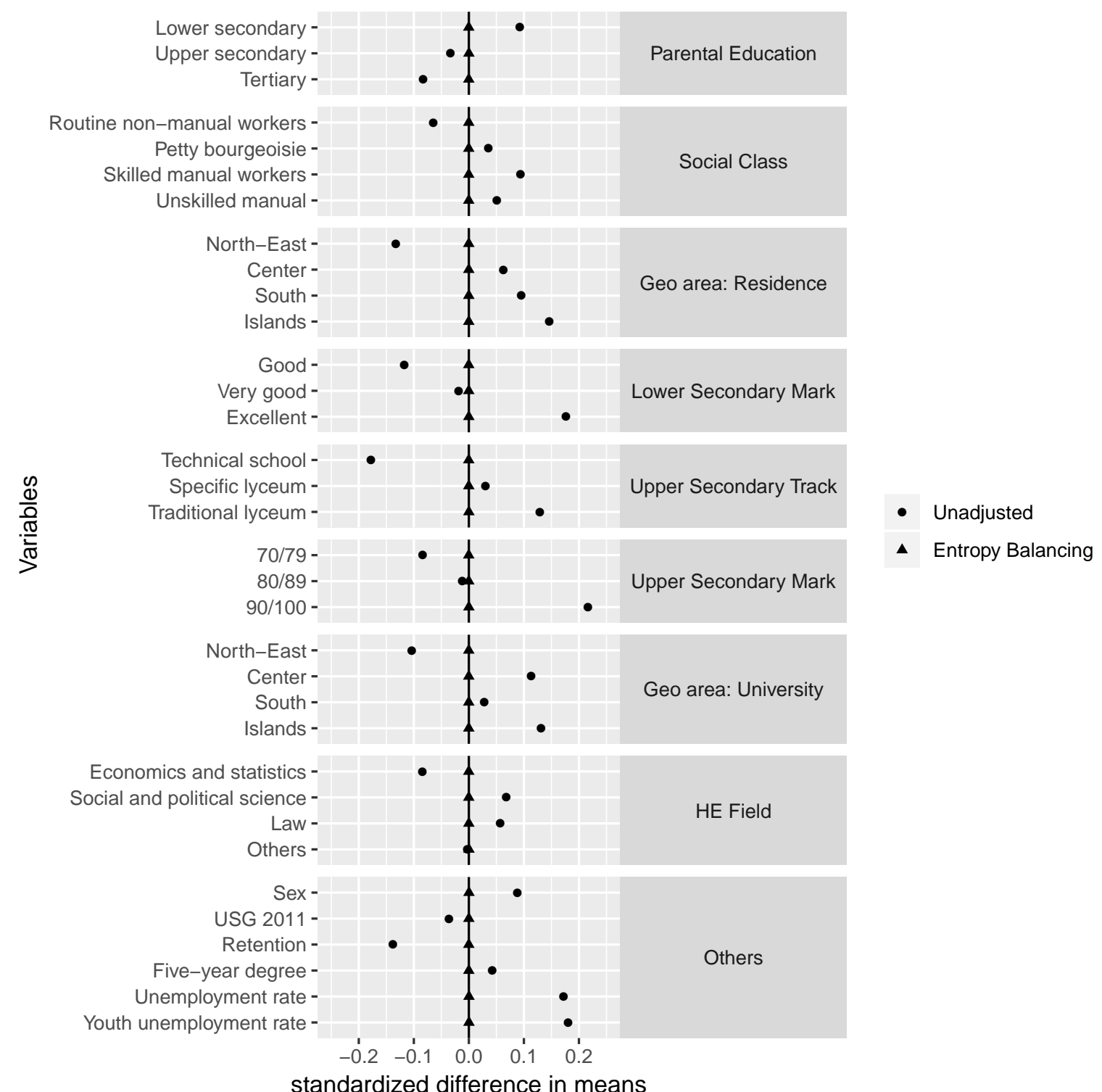

Source: authors' elaboration on ISTAT-USG data. 
the grant's effect using a kernel matching estimator. The final value of the ATT is the average of the ATTs estimated repeating the simulation 500 times.

\section{Empirical Findings}

\subsection{The Effect of Grants on Student Outcomes}

In this section, we assess the impact of grants on tertiary degree attainment using matching techniques. Figure 2 reports the average effects of grants on university dropout (on the left) and timely graduation (on the right). The figure displays the overall effects and heterogeneous effects by gender and geographical area.

First, we observe that financial support significantly diminishes the risk of leaving university without a degree. On average, having received the grant decreases a student's probability of dropping out from 0.116 to 0.032 , an effect of about 8 percentage points (see table A.3 in appendix). Second, receiving aid raises the odds of graduating on time: a student's probability of timely attaining the tertiary degree increases by 11.1 percentage points, up to 0.408 (see Table A.4 in the appendix). These results corroborate the expectation formulated in hypothesis 1a and go against the contrasting hypothesis 1b. Even if we are not in the position to identify the exact mechanisms through which these effects are achieved, they have notable policy implications. Indeed, our results point out that âĂŞ despite the selection processes occurring in secondary education âĂŞ interventions implemented in higher education can still have positive and remarkable effects on educational outcomes.

\subsection{Heterogeneity of the Impact of Grants}

Higher education is substantially diverse in Italy and in order to understand if grants work it is important to investigate their relative efficacy across different types of students (Dynarski and Scott-Clayton 2013). In this section, we explore the heterogeneity of the effect according to the geographical area of the university (northern Italy vs central and southern Italy) and the gender of the recipients. We compare the treated and control groups of each subsample.

We hypothesize that the effect of financial aid could be different for the students who attended university in Southern Italy, where the rate of eligible students that do not receive the grant due to lack of economic resources of the Regional Authority for the Right to Education is remarkably high (see Table A.2 in the appendix). Therefore, financial aid is awarded to the students who are in the lowest portion of the income distribution. Specifically, the effect of financial aids could be higher in the South of Italy, since the students that receive the grant have stronger liquidity constraints. Alternatively, the impact of aid could be lower or null, if the amount of money awarded is too small to counteract the economic difficulties of poorer students.

First, we observe that financial support diminishes the probability of dropout in both geographical areas. However, the intensity of the effect is substantially different. As Figure 2 shows, having obtained the grant decreases a student's probability of dropout in Northern Italy from 0.098 to 0.046 , a change of about 5 percentage points, and in Southern Italy from 0.126 to 0.026 (-10 percentage points). Thus, the estimated impact of grants is almost double in the Southern regions compared to the North. Second, we examined the effect on timely 
Figure 2: Average treatment effect on the treated (ATT) (and 95\% confidence intervals) of student grants: overall effect and heterogeneous effects by geographical area and gender from matching analysis.
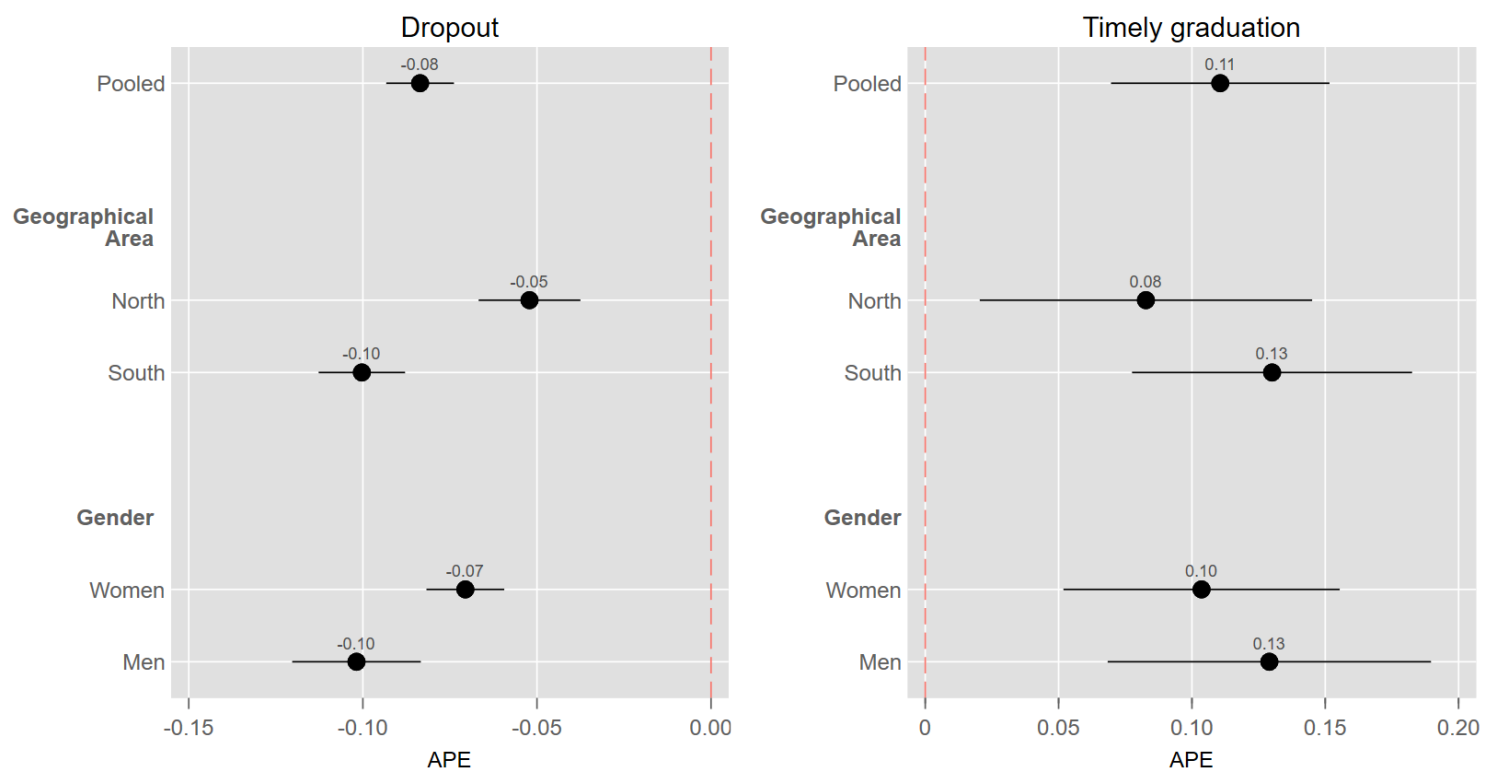

Source: authors' elaboration on ISTAT-USG data.

graduation. Figure 2 reports that a student's chances of completing the degree on time improve by 8.3 percentage points in Northern Italy, starting from 0.482 , and by 13 percentage points in Southern Italy, up to 0.330. However, the estimates of the grant effects in the North and South of Italy partially overlap, due to large sample uncertainty.

We can conclude that the effect of aid on dropout is distinctly higher in Central and Southern Italy. A possible explanation is that in southern regions the students that receive the grants need more support to cover university direct and indirect costs, because of their more disadvantaged economic situation. Notably, while a student has a higher probability of dropping out in the South and her chances of timely attaining the tertiary degree are halved, this context does not hinder the compensating role of financial aid.

Looking at the second dimension, we are interested in understanding whether the effect of aid varies on the basis of gender. Female students are considered on average more motivated and tend to have better academic performance. Therefore, we would expect that for women financial aid would be less crucial to avoid dropout, in comparison with male students, who are often more at risk of study withdrawal.

The results indicate that financial support in the form of student grants decreases the probability of dropout for both genders. Figure 2 shows that having obtained the grant reduces a student's probability of dropout from 0.097 to 0.026 for women, a change of 7 percentage points, and from 0.147 to 0.045 (-10 percentage points) for men. Thus, looking at the point estimates we found some support for our expectation of larger effects among women; despite confidence intervals partially overlap, we tested whether the difference between the 
two coefficients is statistically significant and we found it is at the $95 \%$ confidence level.

Second, we examined the effect of financial aid on timely graduation. On average, having obtained the grant increases a student's probability of graduating on time from 0.332 to 0.436 for women $(+0.104)$, and from 0.230 to $0.359(+0.129)$ for men. In this case, even if the pattern goes in the expected direction, the uncertainty around the point estimates does not allow us to reject the null hypothesis of similar impact by gender.

As a last step of the main analysis, we compared our estimated effects to those found previous by local studies on the Italian context. Figure 3 displays the benchmarking of our estimates, comparing the ATT in our study with those found by the previous research. The value of the estimated effect of aid on dropout holds a central position within the range of previous estimates. Instead, the estimated effect of grant on timely degree is located at the lower bound of the distribution of previous estimates. Our relatively low estimate could be due to the inclusion of more universities in the sample and to the collecting method of USG 2011. Indeed, the questionnaires were administered until October 2011, six months before the end of the fourth academic year, leading to a downward bias.

\subsection{Sensitivity Checks}

We did several checks to assess the robustness of our findings. First, we tried different specifications of the models, changing the number of control variables, the categories in which they are measured and their reciprocal interactions. Second, we used also classical matching procedure to pre-process the data before the estimation on the grant effects. The results are robust to these alternative methodological choices (see Table A.6 and A.7 in the appendix).

Lastly, following Nannicini et al. (2007), we tested the sensitivity of the estimates modelling the potentially unobserved variable using as a reference for its 'behavior' the following variables: final mark in high school and middle school, parental education, track, geographical area of university, sex and grade retention. The outcome effect $(\Gamma)$ corresponds to the average odds ratio of the unknown variable $U$ on $(Y=1 \mid D=0, U, S)$, where $\mathrm{S}$ is the set of covariates. The selection effect $(\Lambda)$ is the average odds ratio of $U$ for the logit model $(D=1 \mid U, S)$. The first row of Table 1 shows the effect of grants on dropouts (first three columns) and timely degree completion (last three columns) in the absence of confounders. In the second row, the confounder mimics the distribution of sex and so forth.

If, for instance, the unobserved variable 'behaved' as sex, it would have a positive effect on the relative probability of receiving the grant $(1.453>1)$ and a negative effect on dropping out $(0.560<1)$. The impact of the grant would be slightly higher than the value estimated using entropy balancing (-0.09) and very near to the ATT computed without confounders. The results further indicate that none of the confounders would substantially change the effect of financial aid on dropout. The same holds concerning timely graduation. In conclusion, the results of the simulations seem to support the analysis presented in this article.

\section{Conclusions}

The aim of this article was to assess whether financial aid, and specifically grants, could be an effective way to reduce social inequalities in students' academic outcomes in higher education in Italy, a context with high levels of dropout, delayed graduations and social inequalities in students' educational careers. The contribution of the paper was, first, to provide a theoretical 
Figure 3: Benchmarking of the estimated effect of student grant on dropout and on timely graduation with previous studies on single Italian universities.

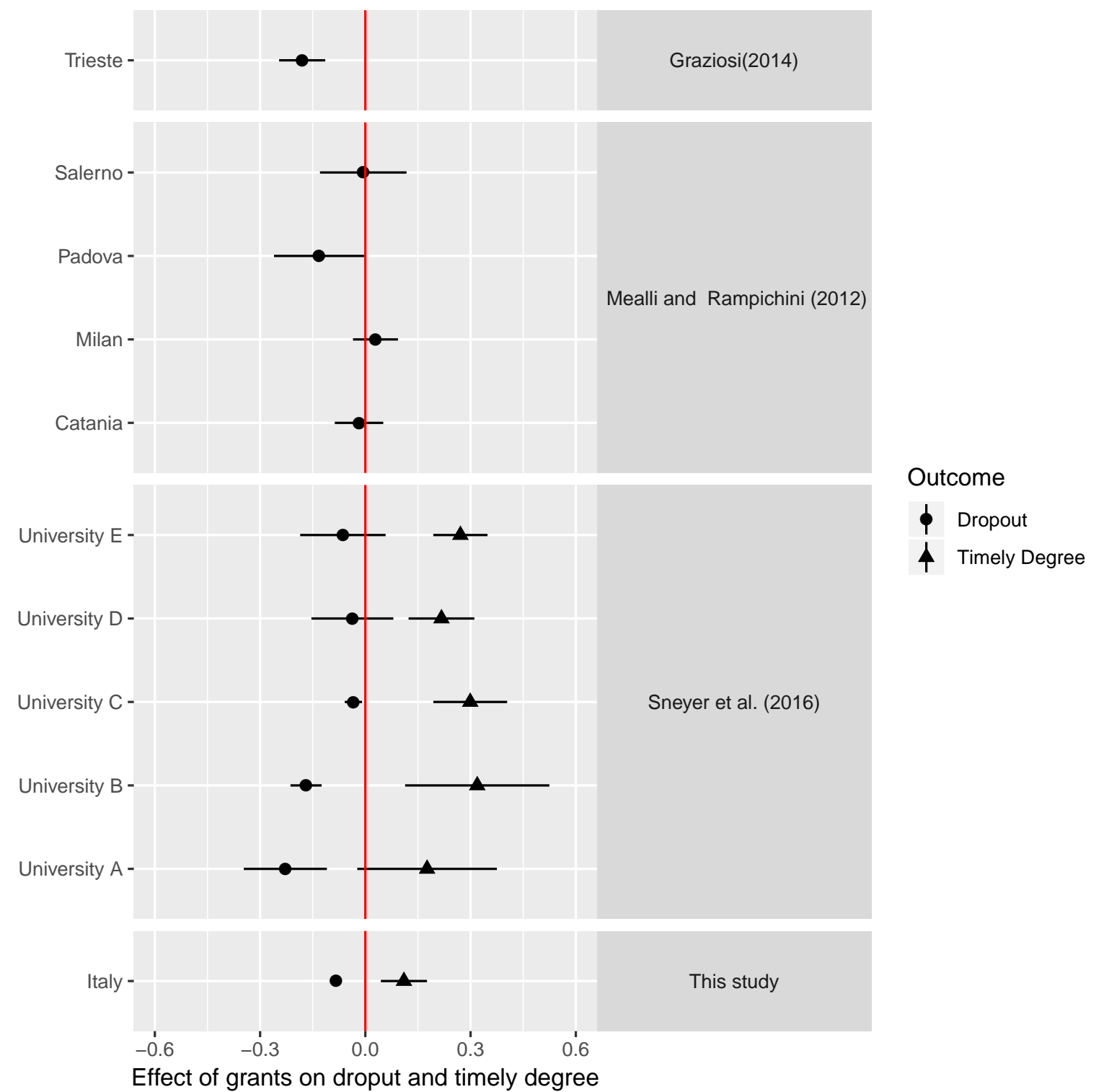

Source: authors' elaboration on ISTAT-USG data. 
Table 1: Sensitivity analysis of the effect of grants on dropout and timely graduation: effect of 'calibrated' confounders.

\begin{tabular}{lcccccc}
\hline & \multicolumn{3}{c}{ Dropout } & \multicolumn{3}{c}{ Timely graduation } \\
\cline { 2 - 7 } & $\begin{array}{c}\text { Outcome } \\
\text { effect }\end{array}$ & $\begin{array}{c}\text { Selection } \\
\text { effect }\end{array}$ & ATT & $\begin{array}{c}\text { Outcome } \\
\text { effect }\end{array}$ & $\begin{array}{c}\text { Selection } \\
\text { effect }\end{array}$ & ATT \\
\hline No confounder & & & -0.104 & & & \\
& & & & & & \\
Confounderlike & & & & & & \\
Sex & 0.560 & 1.453 & -0.101 & 1.501 & 1.352 & 0.148 \\
Top final mark in high school & 0.346 & 1.747 & -0.097 & 2.681 & 1.775 & 0.140 \\
Good final mark in high school & 0.407 & 1.713 & -0.097 & 2.610 & 1.682 & 0.141 \\
Top final mark in middle school & 0.256 & 1.454 & -0.100 & 2.514 & 1.571 & 0.143 \\
Good final mark in middle school & 0.319 & 1.389 & -0.099 & 2.432 & 1.484 & 0.144 \\
High parental educational attainment & 0.406 & 0.583 & -0.106 & 1.678 & 0.596 & 0.152 \\
Low parental educational attainment & 1.790 & 1.433 & -0.105 & 0.686 & 1.439 & 0.151 \\
Academic track & 0.280 & 1.121 & -0.102 & 2.068 & 1.139 & 0.148 \\
Central or Northern University & 1.423 & 1.239 & -0.104 & 0.349 & 1.266 & 0.152 \\
Central or Southern University & 1.318 & 1.185 & -0.104 & 0.422 & 1.228 & 0.152 \\
Grade retention & 2.711 & 0.715 & -0.102 & 0.309 & 0.847 & 0.149 \\
\hline
\end{tabular}

Source: authors' elaboration on ISTAT-USG data.

discussion on the potential effects of grants to students. We highlighted that, while several arguments suggest that providing financial aid to students could improve their outcomes, the positive impact of support should not be taken for granted. Indeed, grants could fail to improve students' outcomes if the transferred money is not sufficient, if the students lack the academic preparation necessary to succeed in university or if the degree course matches poorly their abilities and aspirations.

We also contributed to the literature showing how to provide credible estimates of the impact of grants on dropout risks and probability of graduating on time using survey data that are representative at the national level. Specifically, using a dataset rich of information on students' background and educational careers, we integrated coarsened exact matching and entropy balancing. In this way, we were able to show that grants are an effective tool to improve students' outcomes in a higher education system characterized by high withdrawal rates and delayed graduations. The effects are not only statistically significant, but also substantially relevant. Given that grants are directed towards relatively high-performing lower class students, our results suggest that well-designed financial aid instruments have the potential of both improving the effectiveness of students' educational careers in university, and reducing social inequalities in higher education by boosting the outcomes of low-income students.

Moreover, we found that the effect of grants might differ according to students' characteristics and context. In line with the previous literature, we found that grants are more effective in reducing dropouts among males, who are usually considered more at risk of university withdrawal. Moreover, grants appear to be more effective in the Southern regions than in the North. Since in the South the lack of funding de facto lowers the income threshold to access grants, financial aid could be targeting a more disadvantaged group of students. Therefore, on the basis of our results, we suggest that increasing the resources of financial aid would improve the effectiveness of higher education, reduce the waste of talent and mitigate the social inequalities in students' outcomes that are related to social background, gender and geographical area of residence. 


\section{References}

Abbiati, G. and Barone, C. (2017). Is university education worth the investment? the expectations of upper secondary school seniors and the role of family background. Rationality and Society, 29(2):113-159.

Agasisti, T. and Murtinu, S. (2016). Grants in italian university: a look at the heterogeneity of their impact on students' performances. Studies in Higher Education, 41(6):1106-1132.

Aina, C., Baici, E., and Casalone, G. (2011). Time to degree: students' abilities, university characteristics or something else? evidence from italy. Education Economics, 19(3):311325 .

Alon, S. and Tienda, M. (2005). Assessing the â̆̆IJmismatchâ $\breve{A}$ hypothesis: Differences in college graduation rates by institutional selectivity. Sociology of education, 78(4):294-315.

Angrist, J., Lang, D., and Oreopoulos, P. (2009). Incentives and services for college achievement: Evidence from a randomized trial. American Economic Journal: Applied Economics, 1(1):136-163.

Arendt, J. N. (2013). The effect of public financial aid on dropout from and completion of university education: evidence from a student grant reform. Empirical Economics, pages $1-18$.

Argentin, G. and Triventi, M. (2011). Social inequality in higher education and labour market in a period of institutional reforms: Italy, 1992-2007. Higher education, 61(3):309-323.

Argentin, G. and Triventi, M. (2015). The north-south divide in school grading standards: New evidence from national assessments of the italian student population. Italian Journal of Sociology of Education, 7(2).

Bettinger, E. (2015). Need-based aid and college persistence: the effects of the ohio college opportunity grant. Educational Evaluation and Policy Analysis, 37(1_suppl):102S-119S.

Blackwell, M., Iacus, S. M., King, G., and Porro, G. (2009). cem: Coarsened exact matching in stata. The Stata Journal, 9(4):524-546.

Castleman, B. L. and Long, B. T. (2016). Looking beyond enrollment: The causal effect of need-based grants on college access, persistence, and graduation. Journal of Labor Economics, 34(4):1023-1073.

Checchi, D. (2016). Rapporto biennale sullo stato del sistema universitario e della ricerca 2016. Technical report, Agenzia Nazionale di Valutazione del Sistema Universitario e della Ricerca.

Credé, M., Roch, S. G., and Kieszczynka, U. M. (2010). Class attendance in college: A meta-analytic review of the relationship of class attendance with grades and student characteristics. Review of Educational Research, 80(2):272-295.

Daniel, H.-D., Schwarz, S., and Teichler, U. (1999). Study costs, student income and public policy in europe. European Journal of Education, 34(1):7-21. 
Deming, D. and Dynarski, S. (2009). Into college, out of poverty? policies to increase the postsecondary attainment of the poor. Technical report, National Bureau of Economic Research.

Denning, J. T. (2017). Born under a lucky star: Financial aid, college completion, labor supply, and credit constraints. Working Paper.

Dynarski, S. and Scott-Clayton, J. (2013). Financial aid policy: Lessons from research. Technical report, National Bureau of Economic Research.

Eurydice (2018). National student fee and support systems in european higher education 2017/18. Technical report, Luxembourg: Publications Office of the European Union.

Finocchietti, G., Ceccarini, I., and Grossi Gondi, S. (2015). Le condizioni di vita e di studio degli studenti universitari. 2012-2015. Technical report, Associazione Rui: Rome.

Gambetta, D. (1987). Were they pushed or did they jump?: Individual decision mechanisms in education. Cambridge University Press.

Goldrick-Rab, S., Harris, D. N., and Trostel, P. A. (2009). Why financial aid matters (or does not) for college success: Toward a new interdisciplinary perspective. In Higher education: Handbook of theory and research, pages 1-45. Springer.

Goldrick-Rab, S., Kelchen, R., Harris, D. N., and Benson, J. (2016). Reducing income inequality in educational attainment: Experimental evidence on the impact of financial aid on college completion. American Journal of Sociology, 121(6):1762-1817.

Hainmueller, J. (2012). Entropy balancing for causal effects: A multivariate reweighting method to produce balanced samples in observational studies. Political Analysis, 20(1):2546.

Häkkinen, I. and Uusitalo, R. (2003). The effect of a student aid reform on graduation: a duration analysis. Technical report, Working Paper, Department of Economics, Uppsala University.

Heckman, J. J. (2006). Skill formation and the economics of investing in disadvantaged children. Science, 312(5782):1900-1902.

ISTAT (2007). Percorsi di studio e di lavoro dei diplomati dellâĂŹanno 2004. aspetti metodologici dellâĂŹindagine. Technical report, ISTAT: Rome.

ISTAT (2011). Percorsi di studio e di lavoro dei diplomati dellâĂŹanno 2007. aspetti metodologici dellâĂŹindagine. Technical report, ISTAT: Rome.

King, G. and Nielsen, R. (2016). Why propensity scores should not be used for matching. Copy at http://j.mp/1sexgVw.

Leuven, E., Oosterbeek, H., and Klaauw, B. (2010). The effect of financial rewards on students' achievement: Evidence from a randomized experiment. Journal of the European Economic Association, 8(6):1243-1265.

Marcum, C. S. (2016). A latex template for socarxiv. 
Marginson, S. (2016). The worldwide trend to high participation higher education: Dynamics of social stratification in inclusive systems. Higher Education, 72(4):413-434.

Mealli, F. and Rampichini, C. (2012). Evaluating the effects of university grants by using regression discontinuity designs. Journal of the Royal Statistical Society: Series A (Statistics in Society), 175(3):775-798.

Nannicini, T. et al. (2007). Simulation-based sensitivity analysis for matching estimators. Stata Journal.

OECD (2010). How many students drop out of tertiary education? highlights from education at a glance 2010. Technical report, OECD Publishing.

OECD (2017). Education at a glance 2017: Oecd indicators. Technical report, OECD Publishing.

OECD (2018). Education at a glance 2018: Oecd indicators. Technical report, OECD Publishing.

Page, L. C., Kehoe, S. S., Castleman, B. L., and Sahadewo, G. A. (2017). More than dollars for scholars: The impact of the dell scholars program on college access, persistence and degree attainment. Journal of Human Resources, pages 0516-7935r1.

Page, L. C. and Scott-Clayton, J. (2016). Improving college access in the united states: Barriers and policy responses. Economics of Education Review, 51:4-22.

Sneyers, E., Agasisti, T., De Witte, K., and Graziosi, G. (2016). The impact of scholarships on studentsâÁŹ performance: a study on five italian universities.

Tinto, V. (1975). Dropout from higher education: A theoretical synthesis of recent research. Review of educational research, 45(1):89-125.

Triventi, M. (2014a). Does working during higher education affect studentsâĂŹ academic progression? Economics of education review, 41:1-13.

Triventi, M. (2014b). Higher education regimes: an empirical classification of higher education systems and its relationship with student accessibility. Quality \& quantity, 48(3):1685-1703.

Triventi, M. and Trivellato, P. (2009). Participation, performance and inequality in italian higher education in the 20th century. Higher Education, 57(6):681-702.

Triventi, M., Vergolini, L., and Zanini, N. (2017). Do individuals with high social background graduate from more rewarding fields of study? changing patterns before and after the âĂŸbologna processâĂŹ. Research in Social Stratification and Mobility, 51:28-40.

Viesti, G. (2016). Università in declino. Un'indagine sugli atenei da Nord a Sud. Donzelli Editore.

Vossensteyn, H., Kottmann, A., Jongbloed, B., Kaiser, F., Cremonini, L., Stensaker, B., Hovdhaugen, E., and Wollscheid, S. (2015). Dropout and completion in higher education in europe: main report. Technical report, European Union. 


\section{A. Appendix}

The reader will find here all the supplementary evidences referred to in the main text. Tables A.1 and A.2 report a set of descriptive evidence regarding the variables used in the analyses. Tables A.3 and A.4 show the point estimates of the effects of the grant on drop-out risk and the probability of timely graduation.

Table A1: Descriptive statistics of the outcomes and the main independent variables used in the analyses according to the year of the survey.)

\begin{tabular}{|c|c|c|c|}
\hline & \multicolumn{3}{|c|}{ Year } \\
\hline & 2007 & 2011 & Total \\
\hline Women & 56.0 & 57.0 & 56.5 \\
\hline \multicolumn{4}{|l|}{ Parental educational attainment } \\
\hline Less than primary/primary education & 3.6 & 2.2 & 2.9 \\
\hline Lower secondary education & 23.5 & 20.6 & 22.0 \\
\hline Upper secondary education & 51.0 & 53.0 & 52.0 \\
\hline Tertiary education & 21.9 & 24.3 & 23.1 \\
\hline \multicolumn{4}{|l|}{ Social class of origin } \\
\hline I-II & 27.0 & 28.1 & 27.5 \\
\hline IIIa & 19.0 & 17.7 & 18.4 \\
\hline IVabc & 15.6 & 15.1 & 15.4 \\
\hline V-VI & 16.5 & 15.6 & 16.1 \\
\hline IIIb-VIIab & 21.9 & 23.5 & 22.7 \\
\hline \multicolumn{4}{|l|}{ Geographical area of residence } \\
\hline North West & 21.5 & 21.1 & 21.3 \\
\hline North East & 15.1 & 15.6 & 15.4 \\
\hline Center & 19.9 & 19.5 & 19.7 \\
\hline South & 30.0 & 31.3 & 30.6 \\
\hline Islands & 13.5 & 12.5 & 13.0 \\
\hline \multicolumn{4}{|l|}{ Final mark in middle school } \\
\hline satisfactory (sufficiente) & 13.7 & 8.1 & 10.9 \\
\hline $\operatorname{good}($ buono) & 27.2 & 25.6 & 26.4 \\
\hline very good (distinto) & 28.5 & 31.0 & 29.7 \\
\hline excellent (ottimo) & 30.7 & 35.4 & 33.0 \\
\hline \multicolumn{4}{|l|}{ High school track } \\
\hline Vocational school & 7.7 & 5.7 & 6.7 \\
\hline Technical School & 33.7 & 29.7 & 31.7 \\
\hline Specific Lyceum & 13.0 & 13.5 & 13.2 \\
\hline Traditional Lyceum & 45.7 & 51.2 & 48.4 \\
\hline \multicolumn{4}{|l|}{ Final mark in high school } \\
\hline $60 / 69$ & 20.1 & 21.8 & 21.0 \\
\hline $70 / 79$ & 24.3 & 25.7 & 25.0 \\
\hline $80 / 89$ & 21.1 & 22.2 & 21.7 \\
\hline $90 / 100$ & 34.4 & 30.3 & 32.4 \\
\hline
\end{tabular}


... the table A1 continues

\begin{tabular}{lccc}
\hline \hline & \multicolumn{3}{c}{ Year } \\
\cline { 2 - 4 } & $\mathbf{2 0 0 7}$ & $\mathbf{2 0 1 1}$ & Total \\
\hline Failure & 13.2 & 10.0 & 11.6 \\
Geographical area of university & & & \\
North West & 21.7 & 21.9 & 21.8 \\
North East & 17.4 & 17.7 & 17.6 \\
Center & 22.9 & 22.8 & 22.9 \\
South & 25.2 & 26.1 & 25.6 \\
Islands & 12.7 & 11.4 & 12.1 \\
Type of Degree & & & \\
Bachelor & 87.9 & 84.3 & 86.1 \\
Five-year degree & 12.1 & 15.7 & 13.9 \\
Field & & & \\
Engineering & 11.0 & 11.3 & 11.2 \\
Economics and Statistics & 13.9 & 15.6 & 14.7 \\
Social and Political Science & 11.7 & 9.5 & 10.6 \\
Law & 10.8 & 9.0 & 9.9 \\
Others & 52.6 & 54.6 & 53.6 \\
Grants & & & \\
received & 9.5 & 8.8 & 9.2 \\
Dropout & 13.8 & 12.3 & 13.1 \\
Graduation & 11.4 & 21.7 & 16.5 \\
\hline N & 14,880 & 13,862 & 28,742 \\
\hline
\end{tabular}

In this paper we rely on coarsened matching and on the entropy balancing method to estimate the causal effect of receiving a grant on drop-out and on timely degree completion. In this section we provide a further robustness check using more traditional approach such as the kernel matching and the inverse probability weighting. Table A.6 reports the estimated ATT according to these two methods. The results are very close to those presented in the main text that were -0.084 for the drop-out and +0.111 for the timely graduation.

In Table A.7 we report a set of statistics for evaluating the goodness of the matching (i.e. the similarity between treated and controls according to the covariates included in the model). We compare the unmatched and the matched samples looking at three statistics. First, we calculate the pseudo- $R^{2}$ for the probability of being treated in the two samples. If the matching works good, we will expect to find a very low pseudo- $R^{2}$ meaning that the observed covariates lose their explanatory power after the matching. Second, we calculate the mean and median bias that can be intended as an indicator that assesses the distance between treated and controls for all the covariates. Also, in this case, if the matching succeeds, we should observe a huge reduction in the bias.

All these statistics indicate that the matching procedure was able to create two equivalent 
Table A2: Descriptive statistics of macro variables

\begin{tabular}{lrrrrrrr}
\hline & $\mathbf{2 0 0 4}$ & $\mathbf{2 0 0 5}$ & $\mathbf{2 0 0 6}$ & $\mathbf{2 0 0 7}$ & $\mathbf{2 0 0 8}$ & $\mathbf{2 0 0 9}$ & $\mathbf{2 0 1 0}$ \\
\hline Unemployment rate & & & & & & & \\
North West & 4.6 & 4.4 & 3.9 & 3.8 & 4.2 & 5.7 & 6.2 \\
North East & 3.9 & 4.0 & 3.6 & 3.1 & 3.4 & 4.6 & 5.4 \\
Center & 6.5 & 6.4 & 6.1 & 5.3 & 6.1 & 7.2 & 7.5 \\
South & 14.2 & 13.7 & 11.9 & 10.4 & 11.4 & 11.9 & 12.7 \\
Islands & 16.1 & 15.2 & 12.7 & 12.0 & 13.3 & 13.6 & 14.4 \\
Youth Unemployment Rate & & & & & & & \\
North West & 14.0 & 14.8 & 13.6 & 13.8 & 13.8 & 20.1 & 22.0 \\
North East & 10.6 & 11.5 & 11.0 & 9.6 & 10.5 & 15.3 & 18.8 \\
Center & 21.4 & 21.2 & 19.8 & 18 & 19.5 & 24.4 & 25.6 \\
South & 36.0 & 37.4 & 33.1 & 30.5 & 31.3 & 34.0 & 37.7 \\
Islands & 40.9 & 41.5 & 36.9 & 36.2 & 38.5 & 39.8 & 40.9 \\
Rate of eligible students & & & & & & & \\
not receiving the grant & & & & & & & \\
North West & 2.6 & 2.3 & 0 & 0 & 0 & 0 & 2.8 \\
North East & 6.9 & 7.8 & 0.6 & 1.0 & 1.3 & 1.2 & 15.0 \\
Center & 10.5 & 8.1 & 5.6 & 9.5 & 4.1 & 0 & 15.0 \\
South & 44.8 & 43.6 & 42.2 & 37.7 & 34.6 & 24.2 & 27.1 \\
Islands & 44.8 & 48.9 & 47.3 & 33.7 & 40.0 & 37.3 & 43.4 \\
\hline N & & & & & & & 28,742 \\
\hline
\end{tabular}

source: Istat and Miur

groups on the basis of observed characteristics. The pseudo- $R^{2}$ is not statistically different from 0 in the matched sample and the mean and median bias drop dramatically after matching. 
Table A3: Probability of dropping out according to treatment status and average treatment effect on the treated (ATT) (and standard errors) of student grants on dropout: overall effect and heterogeneous effects by geographical area and gender from matching analysis

\begin{tabular}{|c|c|c|c|c|c|}
\hline & \multicolumn{4}{|c|}{ Probability of dropping out } & \multirow[b]{2}{*}{$\mathbf{N}$} \\
\hline & without grants & with grants & APE & & \\
\hline Pooled data & 11.6 & 3.2 & $\begin{array}{c}-8.4 \\
(0.5)\end{array}$ & $* * *$ & 19.263 \\
\hline \multicolumn{6}{|l|}{ Geographc Area } \\
\hline North Italy & 9.8 & 4.6 & $\begin{array}{c}-5.3 \\
(0.7)\end{array}$ & $* * *$ & 10.515 \\
\hline Center and South Italy & 12.6 & 2.6 & $\begin{array}{r}-10.0 \\
(0.6)\end{array}$ & $* * *$ & 8.748 \\
\hline \multicolumn{6}{|l|}{ Gender } \\
\hline Women & 9.7 & 2.6 & $\begin{array}{r}-7.1 \\
(0.6)\end{array}$ & $* * *$ & 12.837 \\
\hline Men & 14.7 & 4.5 & $\begin{array}{r}-10.2 \\
(0.9)\end{array}$ & $* * *$ & 6.411 \\
\hline
\end{tabular}

Significance Levels : $\quad *: 10 \% \quad * *: 5 \% \quad * * *: 1 \%$

Note: the table displays in parentheses the standard error, calculated with the delta method. Source: USG Istat $(2007,2011)$ 
Table A4: Probability of timely graduation according to treatment status and average treatment effect on the treated (ATT) (and standard errors) of student grants on timely graduation: overall effect and heterogeneous effects by geographical area and gender from matching analysis

\begin{tabular}{|c|c|c|c|c|}
\hline & \multicolumn{3}{|c|}{ Probability of timely graduation } & \multirow[b]{2}{*}{$\mathbf{N}$} \\
\hline & without grants & with grants & APE & \\
\hline Pooled data & 29.7 & 40.8 & $\begin{array}{l}11.1^{* * *} \\
(2.1)^{*}\end{array}$ & 6.131 \\
\hline \multicolumn{5}{|l|}{ Geographc Area } \\
\hline North Italy & 48.2 & 56.4 & $\begin{array}{l}8.3^{* * *} \\
(3.2)\end{array}$ & 3.425 \\
\hline Center and South Italy & 20.0 & 33.0 & $\begin{array}{l}13.0^{* * *} \\
(2.7)^{*}\end{array}$ & 2.691 \\
\hline \multicolumn{5}{|l|}{ Gender } \\
\hline Women & 33.2 & 43.6 & $\begin{array}{l}10.4^{* * *} \\
(2.6)\end{array}$ & 4.352 \\
\hline Men & 23.0 & 35.9 & $\begin{array}{l}12.9^{* * *} \\
(3.1)\end{array}$ & 1.772 \\
\hline
\end{tabular}

Significance Levels : $\quad *: 10 \% \quad * *: 5 \% \quad * * *: 1 \%$

Note: the table displays in parentheses the standard error, calculated with the delta method. Source: USG Istat 2011

Table A5: ATT estimates with alternative methods.

\begin{tabular}{lllllc}
\hline & \multicolumn{2}{c}{ Drop-out } & \multicolumn{2}{c}{ Drop-out } & \\
\cline { 2 - 5 } & ATT & S.E. & ATT & S.E. & Stata routine \\
\hline Kernel matching (caliper) & $-0.094^{* * *}$ & 0.005 & $0.149^{* * *}$ & 0.016 & psmath2 \\
IPW regression adjustment & $-0.097^{* * *}$ & 0.006 & $0.130^{* * *}$ & 0.022 & teffect \\
\hline Significance Levels : $*: 10 \%$ & $* *: 5 \%$ & $* * *: 1 \%$ & \\
& \multicolumn{5}{c}{ Source: USG data }
\end{tabular}


Table A6: Goodness of the matching procedure.

\begin{tabular}{lcccccc}
\hline & \multicolumn{3}{c}{ Drop-out } & \multicolumn{3}{c}{ Drop-out } \\
\cline { 2 - 6 } & Pseudo-R $R^{2}$ & Mean Bias & Median Bias & Pseudo- $R^{2}$ & Mean Bias & Median Bias \\
\hline Unmatched & $0.039^{* * *}$ & 7.5 & 6.7 & $0.046^{* * *}$ & 8.3 & 6.5 \\
Matched & 0.002 & 1.7 & 1.5 & 0.002 & 1.6 & 1.2 \\
& & & & & \\
\hline Significance Levels : & $*: 10 \%$ & $* *: 5 \%$ & $* * *: 1 \%$ \\
& & & Source: USG Istat $(2007,2011)$
\end{tabular}

\author{
Affiliation: \\ Marta Facchini \\ Observatoire Sociologique du Changement \\ Sciences Po \\ Paris, France \\ E-mail: marta.facchini@sciencespo.fr
}

